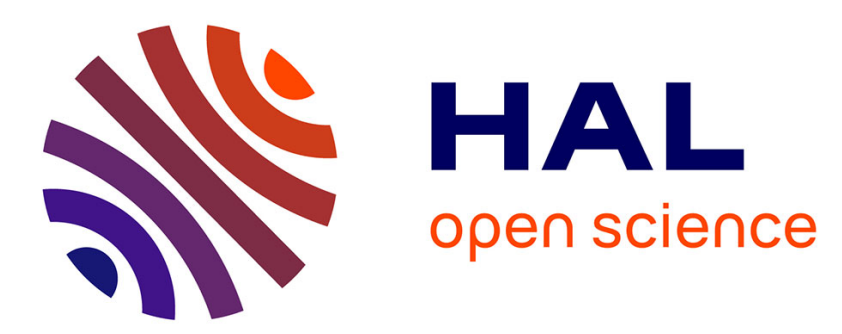

\title{
The pragmatic functions of the final particle eh and of High Rising Terminals in Canadian English: quite similar, eh!
}

Clara Rodrigues da Mota, Sophie Herment

\section{To cite this version:}

Clara Rodrigues da Mota, Sophie Herment. The pragmatic functions of the final particle eh and of High Rising Terminals in Canadian English: quite similar, eh!. International Conference on Speech Prosody, May 2016, Boston, Unknown Region. 10.21437/SpeechProsody.2016-180 . hal-01462239

\section{HAL Id: hal-01462239 \\ https://hal.science/hal-01462239}

Submitted on 28 Mar 2018

HAL is a multi-disciplinary open access archive for the deposit and dissemination of scientific research documents, whether they are published or not. The documents may come from teaching and research institutions in France or abroad, or from public or private research centers.
L'archive ouverte pluridisciplinaire HAL, est destinée au dépôt et à la diffusion de documents scientifiques de niveau recherche, publiés ou non, émanant des établissements d'enseignement et de recherche français ou étrangers, des laboratoires publics ou privés. 


\title{
The pragmatic functions of the final particle $e h$ and of High Rising Terminals in Canadian English: quite similar, eh !
}

\author{
Clara Rodrigues Da Mota \& Sophie Herment \\ Aix-Marseille University, Laboratoire Parole et Langage, Aix-en Provence, France \\ clara.damota@yahoo.fr, sophie.hermenteuniv-amu.fr
}

\begin{abstract}
The starting point of the present analysis is the recurrent use of $e h$ in spoken Canadian English. We based our study on oral data from two different sources: recordings of spontaneous conversations by Canadian speakers and two DVDs of humorous shows. The analysis of the corpus attracted our attention on another widely spread phenomenon in Canadian English: the use of high rising terminals (HRTs). The present paper shows that it proves relevant to link the use of the final particle $e h$ when used as a discourse marker and HRT. We based our observations on qualitative analyses of talk-ininteraction. The purpose of this research is an attempt to account for the use of $e h$ and HRT by focusing on different pragmatic aspects allowing us to understand and define them better. The extensive analysis of both features of Canadian English reveals that their function is truly comparable and shows that HRT, which is an intonation contour, can play the role of a final particle. Or is it the opposite?
\end{abstract}

Index Terms: Canadian English, Canadian eh, HRT, final particles, speech markers, pragmatic functions.

\section{Introduction}

The starting point of the present analysis is the recurrent use of $e h$ in spoken Canadian English. $E h$ is widely known and used in North America [1], and it has also been reported as very common in New Zealand ([2], [3], [4]). According to [5], it is present in many varieties of English, would find its origin in England, and would date back a long time, as it has been found in Chaucer's writings. However, eh is commonly perceived as one of the linguistic features characterizing Canadian English. Both Canadians and people from the United States view it as one of the distinctive features of oral Canadian English (see [5] [6] [7]). A number of studies have already been carried out on the use of $e h$ in Canada (cf. [5], [6], [8], [9], [10], [11], [12]). [8] uses the term "question particle", [2] talks of a "pragmatic particle", [13] refers to the "Canadian tag eh". Eh is also referred to as a discourse marker. Those various terms no doubt apply to $e h$ in Canadian English, but the terminology probably depends on the use of $e h$. It can indeed sometimes be substituted by a question tag, in What a game, eh? for example, or by a discourse marker like you know in this example by [9] See, what I used to do with mine, I have a seven-inch reel at home too eh, now all tape recorders work the same way,... and eh is linked to the question in What are you trying to say eh? for instance. We see that $e h$ can take several values but from a global perspective, $e h$ being final in the sentence, we consider like $[29$, p. 29] that it is a sentence final discourse particle (SFP).
The analysis of the corpus attracted our attention on another widely spread phenomenon in Canadian English: the use of high rising terminals (HRTs). Many studies deal with their growing usage in several varieties of English. HRT is the use of a rising intonation where a fall would be expected. It was first reported in Australia and New Zealand (see [14], [15] [16], [17], [18], [19], [20]), then North America (see amongst others [21] [22] [23] for the USA and [24], [25] for Canada), and is now spreading in Great Britain as well ([26], [27]). However, to the best of our knowledge, no study has tried to relate the two phenomena. It has often been noted that in tone languages, sentence-final discourse particles and intonation are related. [28] and [29] show that SFPs in tone languages have meanings that are closely equivalent to those expressed through intonation in other languages. Our hypothesis is that in Canadian English, an intonation language, the SFP $e h$ and HRTs share a number of semantic and pragmatic values, although they may seem orthogonal entities, the former being a final particle and the latter an intonation contour. Indeed a thorough analysis of the corpus provided a number of similarities which cannot be ignored.

\section{Corpus and method}

In order to study both of these phenomena, we built a 2-hour corpus of recordings of spontaneous conversations by Canadian speakers who were aged 20 to 22 years old. In one recording they speak together and in other recordings, interviews were conducted by the first author, involving only one speaker at a time. Unfortunately, no occurrence of $e h$ was found in the conversations, except those elicited by particular questions ( $c f$. sf1). This is the reason why we had to add to our data two DVDs of humorous shows ([30], [31]), where occurrences of eh were present. However, this is semispontaneous speech and in a very particular situation.

The corpus contains 317 occurrences of eh and 194 occurrences of HRTs. We based our findings on qualitative analyses of talk-in-interaction.

Sound File 1 (sfl) gives a better idea of HRT: the speaker is asked to define Canadian English; in her answer, she insists on the recurrence of the marker $e h$ and while doing this, she makes rising terminal intonations.

In the DVDs, where $e h$ is recurrent, it was striking to hear that most occurrences of $e h$ were pronounced with a rising intonation too, even in declarative contexts. Out of our 317 occurrences of $e h$, only a few are pronounced on a rather flat tone, and always in the expression "Good day eh" (sf20 is one example). All the other occurrences are rising. The two phenomena seemed to be closely related and our hypothesis was that they had similar functions, and that this would 
explain why eh tends not to appear in the speech of young people, who make great use of HRTs.

\section{Discourse marker $e h$ and HRT: same types of glosses and economy}

As we have seen in the introduction, eh can take several values. It is divided into eight categories by [5] and [9], and ten categories by [10], among which we find $e h$ used as a tag, $e h$ after an exclamation, a polar interrogative, a whinterrogative, pardon $e h$, etc. We focus in this paper only on the category called 'anecdotal $e h$ ' by [9] and 'narrative $e h$ ' by [10], where $e h$ is a discourse marker and which is most typical of the Canadian use of $e h$. This is the category of $e h$ used in declaratives, which is therefore comparable with HRTs. The main property allowing us to connect the two phenomena is that both of them can be glossed in a similar way, and that they allow the speaker to make economy.

\subsection{Glosses}

Both $e h$ and HRTs could be replaced by glosses like you know, okay, you know what I mean.

Sf2 Okay you know his replacement eh like the new boss, we made the appointment with him eh what's his name again?

In this example, it is possible to gloss or at least to assert that eh provides the same content as you know or you know what I mean. There is indeed an occurrence of you know beforehand and eh echoes the occurrence of you know which precedes it.

$\mathrm{Sf} 3$ is an example of HRT:

Sf3 uh I was born in Toronto but I went to school in a town called St Catharines

The rise on St Catharines can probably be explained by the fact that $\mathrm{S}$ (the speaker) wishes to make sure his cospeaker (the interviewer in this particular context, who is not Canadian) knows this small city. He assumes that the cospeaker may not know it and the HRT functions as a way to integrate the question you know?, you know what I mean? to the declarative sentence. If $e h$ had been integrated in this sentence, there would probably have been a fall on $S t$ Catharines and a rise on eh only, as is very often the case with eh (see 5.2).

[4] questions the Canadian traditional approach of $e h$, that is to study $e h$ as if it were carrying an implicit question. Instead she favors a completely different approach. She describes $e h$ as a means to make sure both speakers share the same knowledge at a given time in the conversation: " $E h$ is hardly a question seeking the transfer of factual information from one speaker to the other; rather, its main function is to realign the interlocutors as members of a group (even if it is only the two of them) with a shared value system [...] Eh focuses on the establishment of shared belief systems or ingroup knowledge.” ([4, p. 378])

This theory can be applied to HRT too, as there is a real idea of realigning, smoothing any difference of knowledge between both speakers. It can be presented as some kind of wish on the part of the speaker to make sure there is no gap/difference of knowledge between themselves and the cospeaker(s).

This concept of realigning the speakers' shared knowledge can be extended to that of economy.

\subsection{Economy}

Eh and HRT allow the speaker to save some time and avoid pronouncing words which would have normally been uttered.

Sf4 D: ok so we just go down the lake side park here eh

Man: that's right that's right at the bottom of the hill

Sf5 even if you want to take French in grade ten there's of course less and less people every year who want to continue when it's not required

Sf6 I mean it was it was a lot better than the regular core class would have been

In all of these cases $e h$ and HRT could be substituted by the same glosses like right?, you know?, are you following $m e$ ?. Both $e h$ and HRT therefore have a stock-taking value. They allow the speaker to avoid using a longer expression or phrase, hence the idea of economy.

It is to be noted that many occurrences of HRTs take place in our corpus on the expressions or anything, and stuff and or whatever. [13] refers to these expressions as a way of ending sentences in Canada, and talks of 'sentence tags'. She classifies them along with $e h$. In all those occurrences, the expression are you following me? or you see what I mean? could be added.

\section{Pragmatic functions}

The final particle $e h$ when used as a discourse marker and HRTs also seem to share similar pragmatic functions in discourse.

\subsection{Speaker's uncertainty}

When using HRT, the speakers seem to integrate a question in a declarative clause. A thorough analysis of the corpus has revealed that in some cases, eh as much as HRT enable the speaker to add uncertainty to what they are saying.

Sf7 D : he's not dead look his stomach's moving

$B$ : maybe he's just sleeping eh

$D$ : maybe he's gonna puke he had too many beers

$B$ : what beers

$D$ : I'll find them

In sf7, the McKenzie brothers get into a room where a man is lying on the floor. Bob and Doug start making assumptions as to the physical condition of this man. When Bob says 'maybe he's just sleeping eh', there is an idea of uncertainty. This idea is already there in the adverb maybe. The occurrence of eh clearly expresses the speaker's uncertainty, it could be replaced by what do you think? Bob encourages his brother to give his opinion, he presents a supposition which is supported by the fact that the man is lying on the floor (and could therefore be sleeping), but at the moment he says that, he cannot be sure about anything.

\section{Sf8 Hard to say coz I don't really recognize when I use it}

In sf8, B is asked when she uses eh. She answers doing an unexpected rise on the pronoun it. The negation associated with the adverb really seems to introduce her uncertainty; if she had said I don't recognize when I use it, she would have had a clear-cut point of view. The fact that there is a rise on it reinforces her uncertainty. She could very well ask herself: $D o$ I actually recognize when I use it? Do I actually use it? I'm not sure about this. One can easily perceive her uncertainty, and she seems to be expressing it through the HRT. Unlike in 
sf7, B does not appeal to her co-speakers for them to confirm what she says.

The next three examples are clear cases of uncertainty, expressed by I think in sf9, I guess in sf10, and or something in sf1 1 and reinforced by the HRT.

Sf9 $K$ : and so now we don't have a car so we can't get to Maastricht so we're going to Grenoble... for a few days I think

Sf10 and then that's the border, right? To the States, to Michigan I guess

sf11 someone was telling me they opened a bank account with the Crédit Lyonnais or something

In sf9 $\mathrm{K}$ rises on I think because she is not sure of what her friends and herself will be doing during the holidays, they should be going to Grenoble but their plans do not seem to be fixed. The first rise, on Grenoble, can express K's uncertainty as to the way this word is pronounced. One could also imagine that she is asking her co-speakers if they know what city she is talking about since she knows that they have just arrived in France and may not know the city of Grenoble.

In sf10, $\mathrm{K}$ is explaining where she comes from. Her cospeakers have general knowledge about Ontario and North America, and $\mathrm{K}$ makes sure they know what she is talking about. The rise on border shows that Kim adds the idea: you know what I mean?. Then there is a rise on the word right as expected. The rise on I guess indicates uncertainty: when $\mathrm{K}$ says and then that's the border, right? she is not quite sure about herself and her uncertainty is highlighted by the rise on $I$ guess.

In sf11, B does a rise on or something because, just like in the previous cases, she is not sure about what she is saying. Either she is not sure about the bank itself: whether that person opened a bank account at the Crédit Lyonnais or at another bank; or she is not sure about the way Crédit Lyonnais is pronounced. Either way, there is uncertainty.

If the idea of uncertainty is present for both phenomena, it is interesting to note that a main difference appears: $e h$ cannot express some sort of self-questioning, the way HRT sometimes can.

- Either $e h$ or HRT can be used when the speaker is not sure about him/herself and asks his/her co-speaker to confirm or revoke what (s)he is saying.

- Only HRT can be used when the speaker is not sure about him/herself but does not appeal to his/her cospeaker.

\subsection{Leaving one's statement open}

Our study also shows that the use of $e h$ and HRT allows the speaker not to close the conversation imposing their point of view. It is a way to give one's opinion while showing that one acknowledges that there are different points of view, so as not to sound peremptory or abrupt and have a moderate discourse. [3, p.160] explains : "In this way [appending $e h$ to a sentence], a speaker can avoid an attitude of officiousness and at the same time avoid unfriendly formality. This interpretation of $e h$ fits well with Canadians' general conception of themselves as a rather cautious, rather retiring, but basically good-hearted nation. We are not afraid to form our own point of view, we just don't like to force it too much on other people. Eh?"
Examples sf12 to sf15 are good illustrations that the definition [3] gives to $e h$ can also be applied to HRT.

Sf12 B: anyway this is the only Canadian stubby you can get eh Red Cap - though they should call it Red Toque coz you can't keep your...

$D$ : it does look kinda like a toque eh

$B$ : well if it has earflaps on it then maybe

Sf13 D: here's a typical Canadian wolf pelt $\underline{\mathrm{eh}}$

Sf14 whereas -with- when they're Americans, foreigners might not be so nice

$\mathbf{S f 1 5}$... or every statement that you make. It makes it seems like a question and then it allows that other person to disagree with you

In sf12 Doug reacts to what Bob has just said, he seems to think alike but when saying eh, he shows that he acknowledges that Bob could have a different point of view from his. $E h$ expresses Doug's politeness, which he wishes to integrate to his words. Doug moderates his words and Bob feels welcome to restrict what Doug has just said: if it has earflaps on it then maybe.

As in sf12, the speaker in sfl3 proves to be open-minded, showing that he accepts that his co-speaker might want to say that it is in fact a gray wolf pelt for example. In addition to that, $e h$ is also a way to hail someone. This reinforces the idea that the speaker saves some words as soon as he uses $e h$, since this marker can entail several feelings at the same time.

In sf14, $\mathrm{K}$ is talking about the difference between Canadians and Americans and the way they are treated by the foreigners. To her, Canadians would enjoy the foreigners' sympathy compared to the Americans. In this case, the rise occurs on the entire ending of the utterance. $\mathrm{K}$ clearly gives her point of view and the rise appears to give a chance to her co-speakers to feel free to show that they disagree.

In sf $15, \mathrm{~K}$ is talking about the eh phenomenon, she is giving her point of view and has a rising intonation on two occasions where a falling intonation could have been expected. The rising intonation could be substituted, adding a phrase like you know?, you know what I mean? for example. Nevertheless this rising intonation can also be justified by the fact that $\mathrm{K}$ does not exclude any other point of view and she therefore explicitly allows, or encourages as [3] would say, her cospeakers to react and give their own opinion if they have any objection whatsoever.

Like for the idea of uncertainty, it is interesting to note that opening one's statements with HRT can be intended to the speaker themselves, as in sf16, which does not seem to be the case with $e h$.

Sf16 Well I've only had I think one teacher whose first language English

This occurrence of HRT marks K's uncertainty, which is already present in $I$ think. It is possible to say that the speaker leaves her statements open in case she needs to adjust (even possibly correct) what she has just said. Opening her statement is not for her co-speakers but for herself since her co-speakers do not know which professors $\mathrm{K}$ is talking about, so they are not able to confirm or revoke anything at all. The reason why she leaves her statement open is for her own sake, as if she wanted to be able to come back on what she had just said in case she remembered some details so that she could have a more accurate discourse, and perhaps toning down her uncertainty. 


\subsection{Combining functions}

Sf17 it's because you can tell exactly where they've studied

$\mathrm{K}$ is talking about her teachers at University in the English department, where they're from and what type of accents they have. She explains that it is easy to know where they have studied when you listen to their accent. The two speakers share the same knowledge because they both know the teachers and in this case, the opening is rather directed to the co-speaker. The idea of are you following me? is part of the declarative sentence but the co-speakers are still able to revoke these words.

\section{Dissimilarities}

\subsection{HRT in reported speech}

Some occurrences of HRT were found in reported speech: when the speaker reports the words of someone else, the rising intonation seems to be justified by the will of the speaker to take some distance towards what he reports, as if they wanted to show that they do not adhere to the words they are reporting, as in sf18 and sf19. Eh could not be inserted in these examples.

Sf18 In fact there's a movie that just came out in... that's going around Canada it's a documentary called everybody no Let's all hate Toronto

$\mathrm{S}$ comes from Toronto and he does not agree with the title of the documentary. The rising intonation insists on the idea that he is just reporting about the existence of this documentary but does not adhere with what is in it.

Sf19 One of my friends from London told me the other day that she wouldn't trust this man as far as she could kick a piano

This is another case of reported speech. $\mathrm{K}$ refers to an expression used by her British friend. The context reveals that she knows this expression and that she finds it extremely archaic. When she tells this anecdote and rises on piano, she wants to show that she has doubts about this expression and that she wants to distance herself from it, to show that she is only reporting, that she herself would not have used it. As a consequence, the act of adding some interrogative feature to her statement sounds as if she were questioning what she is reporting. This function of HRT does not seem to apply to $e h$.

\subsection{Rising $e h$ and HRT}

We already said that one of the similarities between 'narrative' or 'anecdotal' $e h$ and HRT is the rising movement. However, it is to be noted that the movement is not the same. The intonation is not HRT when $e h$ is pronounced. With $e h$, we either find a rising movement on the word preceding $e h$, and then another rise on $e h$, as in sf21 (figure 1 below):

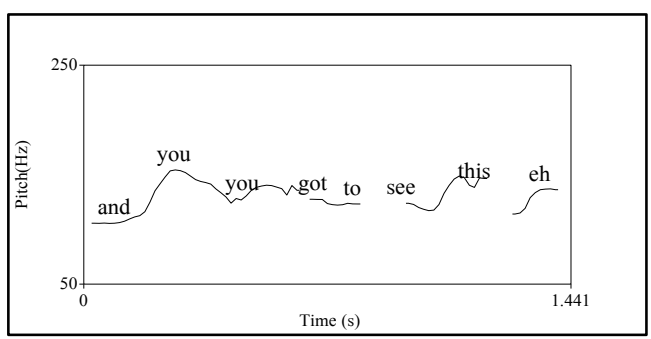

Figure 1: rising eh after a rise (sf21)
We can also find, and this is the most common case, a falling intonation on the word preceding $e h$, and then a rise on $e h$, which is a post nuclear syllable. So the tone is a fall-rise as can be seen in Figure 2 (sf22):

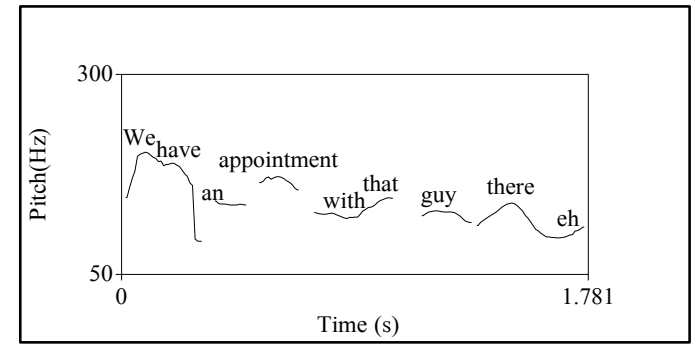

Figure 2: rising eh after a fall (sf22)

In HRTs, the movement is quite different since we find a rather flat intonation preceding the rise, and the rise is quite sharp as exemplified in figure 3 (sfl1). The rise can also expand on several syllables, as in sf9 for instance.

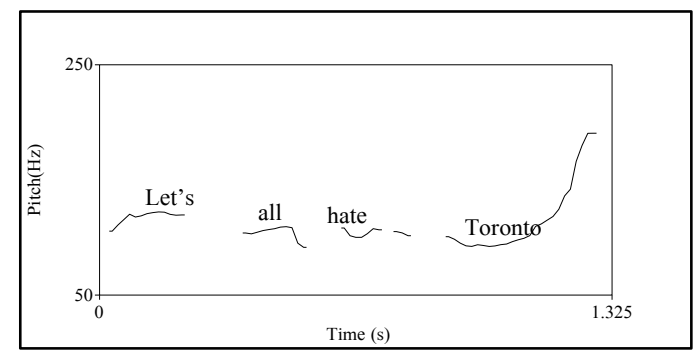

Figure 3: HRT (sf18)

\section{Conclusion}

It was interesting to compare two phenomena which first seem quite distant from one another. The final discourse particle $e h$ when used as a discourse marker and the intonation contour known as HRT share a number of features:

- They have similar glosses

- They both share a notion of economy

- They both express the speaker's uncertainty

- And they both allow him/her to open his/her statements

There are nevertheless differences and in particular the fact that HRT carries an idea of reciprocity which eh does not.

Our study shows that in an intonation language like English SFPs exist and that an SFP and an intonation contour can have similar pragmatic functions in the same language. An intonation contour could therefore act as a discourse marker, or would it be the other way round, i.e. an SFP would function like an intonation contour? The two phenomena do not overlap, speakers use either one or the other. If they use $e h$, the intonation contour is not an HRT.

In terms of perspectives, it would be interesting to analyze spontaneous occurrences of eh, which, as was shown, are difficult to catch. It would be relevant to analyze varied data, so as to see if speakers use more HRTs or more occurrences of eh according to age, sex, speech styles, or other criteria. Comparing with other varieties of English could also prove relevant, especially in the perspective of testing the pragmatic functions found here for HRT. Finally, comparing other SFPs like for example hein in French (cf. [10]) or lah in Singapore English (cf. [32]) could help better understand how SFPs are used in languages that are not tone languages. 


\section{References}

[1] D.J. Gibson, A thesis on eh. Unpuplished M.A. thesis, Department of Linguistics, University of British Colombia 1976.

[2] Meyerhoff, Miriam, "Sounds pretty ethnic, eh?: a pragmatic particle in New Zealand English". Language in Society vol. 23 no. 3, pp. 367-88, 1994.

[3] M. Stubbe and J. Holmes, "You know, eh and other 'exasperating expressions': an analysis of social and stylistic variation in the use of pragmatic, devices in a sample of New Zealand English". Language and Communication vol. 15, no. 1, pp. $63-88,1995$

[4] D. Starks, L. Thompson \& J Christie, "Whose discourse particles? New Zealand eh in the Niuean migrant community". Journal of Pragmatics vol. 40, pp. 1279-95, 2008.

[5] Avis, Walter, "So Eh? is Canadian, Eh?", in Essays and Articles, Walter S. Avis, Ed. Kingston: Royal Military College of Canada, 1972, pp. 172-90.

[6] A.B. Harold, "Canadian American speech differences along the middle border", Journal of the Canadian Linguistic Association vol. 5, pp. 17-24, 1959.

[7] S. Clarke, "Nooz or nyooz?: The complex construction of Canadian identity". Canadian Journal of Linguistics/Revue canadienne de linguistique vol. 5, no. 2, pp. 225-246, 2006.

[8] T. Love, An examination of eh as question particle, Honours Thesis, University of Alberta, 1973

[9] D.J. Gibson, "Eight types of 'eh"”, Sociolinguistics Newsletter vol. 8, pp. 30-31, 1977.

[10] E. Gold \& M. Tremblay, "Eh? and Hein?: Discourse particles or national icons?" Canadian Journal of Linguistics/Revue canadienne de linguistique, vol. 51, no. 2, pp. 247-63, 2006.

[11] E. Gold, "Canadian Eh? From Eh to Zed", Anglistik vol. 19, no. 2, pp. 141-56, 2008.

[12] M. Johnson, "Canadian Eh", Working Papers in Linguistics vol. 21, pp. 153-160, Ohio State University, 1976.

[13] S.A. Tagliamonte, "'So cool, right?': Canadian English entering the 21 st century", Canadian Journal of Linguistics/Revue canadienne de linguistique vol. 5, no. 2, pp. 309-331, 2006.

[14] R.L. Mac Gregor, 'The social distribution of an Australian English intonation contour', Working Papers, vol. 2, no. 6, pp. 126, Macquarie University, School of English and Linguistics, 1980 .

[15] G. Guy \& J. Vonwiller, "The meaning of an intonation in Australian English", Australian Journal of Linguistics vol. 4, pp. 1-17, 1984.

[16] G. Guy et al., "An intonational change in progress in Australian English." Language in Society vol. 15, pp. 23-51, 1986.

[17] S. Allan, "The rise of New Zealand intonation", in New Zealand ways of Speaking English, A. Bell \& J. Holmes, Eds. Clevendon: Multilingual Matters, 1990, pp. 115-128.

[18] D. Britain \& J. Newman, "High rising terminals in New Zealand English." Journal of the International Phonetic Association vol. 22, pp. 1-11, 1992.

[19] D. Britain, "Linguistic Change in Intonation: the use of High Rising Terminals in New Zealand English." Language Variation and Change vol. 4, pp. 77-104, 1992.

[20] D. Britain, "High Rising Terminals in New Zealand English: Who uses them, when and why?" Essex Research reports in Linguistics, pp. 33-58, 1998.

[21] M.K.L. Ching, "The question intonation in assertions", American Speech vol. 57, pp. 95-107, 1982.

[22] A. Arvaniti \& G. Garding. "Dialectal variation in the rising accents of American English", in Papers in Laboratory Phonology 9: Change in Phonology, J. Cole \& J. H. Hualde, Ed. Berlin: Mouton de Gruyter, 2007, pp. 547-576.

[23] A. Ritchart \& A. Arvaniti, "The form and use of uptalk in Southern Californian English." Proceedings of the $7^{\text {th }}$ International Conference on Speech Prosody, Dublin May 20-23 2014, pp. 331-335.
[24] V. Shokeir, "Evidence for the stable use of uptalk in Ontario English." University of Pennsylvania Working Papers in Linguistics vol. 14, pp. 16-24, 2008.

[25] E. James, C. Mahut \& G. Latkiewicz, "The investigation of an apparently new intonation pattern in Toronto English." Information Communication vol. 10, pp. 11-17, 1988.

[26] A. Cruttenden, Intonation, Cambridge: Cambridge University Press, 1986.

[27] D.R. Ladd, Intonational Phonology, 2nd edition, Cambridge: Cambridge University Press, 2008.

[28] S.C. Yau, "Sentential connotations in Cantonese". Fangyan, vol. 1, pp. 35-52, 1980

[29] J.C. Wakefield, The English equivalents of Cantonese sentencefinal particles: A contrastive analysis. Ph.D. thesis, Hong Kong Polytechnic University, 2010.

[30] DVD: Bob \& Doug McKenzie's Two-Four Anniversary. Dir. Henry Sarwer-Foner. Vivendi Visual Entertainment Canada, 2007.

[31] DVD: Strange Brew. Dir. Rick Moranis Dave Thomas. MetroGoldwyn-Mayer, 1983.

[32] J. S. German \& L. Prévot, "Phonology constrains the distribution of the particle lah in Singapore English", Poster presented at LabPhon 14, Tokyo, 25-27 July 2014. 